\title{
Evidence of a lysosomal pathway for apoptosis induced by the synthetic retinoid CD437 in human leukemia HL-60 cells
}

\author{
Y Zang $^{1}$, RL Beard ${ }^{2}$, RAS Chandraratna ${ }^{2}$ and JX Kang ${ }^{\star, 1}$ \\ 1 Department of Medicine, Massachusetts General Hospital and Harvard Medical \\ School, Boston, MA 02114, USA \\ 2 Retinoid Research, Allergan Pharmaceuticals, Irvine, CA 92713, USA \\ * Corresponding author: JX Kang, Massachusetts General Hospital, Room \\ 4433, 149 13th Street, Charlestown, MA, USA. Tel: (617) 726-8509; \\ Fax: (617) 726-6144; E-mail: kang.jing@mgh.harvard.edu
}

Received 13.11.00; revised 21.12.00; accepted 8.1.01

Edited by AM Jetten

\section{Abstract}

The novel synthetic retinoid 6-[3-(1-adamantyl)-4-hydroxyphenyl]-2-naphtalene carboxylic acid (AHPN/CD437) has been proven to be a potent inducer of apoptosis in a variety of tumor cell types. However, the mechanism of its action remains to be elucidated. Recent studies suggest that the Iysosomal protease cathepsin $D$, when released from lysosomes to the cytosol, can initiate apoptosis. In this study, we examined whether cathepsin $D$ and free radicals are involved in the CD437-induced apoptosis. Exposure of human leukemia HL-60 cells to CD437 resulted in rapid induction of apoptosis as indicated by caspase activation, phosphatidylserine exposure, mitochondrial alterations and morphological changes. Addition of the antioxidants $\alpha$ tocopherol acetate effectively inhibited the CD437-induced apoptosis. Measurement of the intracellular free radicals indicated a rise in oxidative stress in CD437-treated cells, which could be attenuated by $\alpha$-tocopherol acetate. Interestingly, pretreatment of cells with the cathepsin D inhibitor pepstatin A blocked the CD437-induced free radical formation and apoptotic effects, suggesting the involvement of cathepsin D. However, Western blotting revealed no difference in cellular quantity of any forms of cathepsin D between control cells and CD437-treated cells, whereas immunofluorescence analysis of the intracellular distribution of cathepsin D showed release of the enzyme from lysosomes to the cytosol. Labeling of lysosomes with lysosomotropic probes confirmed that CD437 could induce lysosomal leakage. The CD437-induced relocation of cathepsin $D$ could not be prevented by $\alpha$-tocopherol acetate, suggesting that the lysosomal leakage precedes free radical formation. Furthermore, a retinoic acid nuclear receptor (RAR) antagonist failed to block these effects of CD437, suggesting that the action of CD437 is RAR-independent. Taken together, these data suggest a novel lysosomal pathway for CD437-induced apoptosis, in which lysosomes are the primary target and cathepsin $D$ and free radicals act as death mediators. Cell Death and Differentiation (2001) 8, $477-485$.

Keywords: CD437; apoptosis; lysosomes; cathepsin D; free radicals

Abbreviations: CD437, 6-[3-(1-adamantyl)-4-hydroxyphenyl]-2naphtalene carboxylic acid; $\Delta \psi_{\mathrm{m}}$, inner mitochondrial transmembrane potential; M6P/IGF2R, mannose 6-phosphate/ insulin-like growth factor-II receptor; RAR, retinoic acid receptor; ROS, reactive oxygen species

\section{Introduction}

Over the last few years, a growing number of studies have shown that the novel synthetic retinoid 6-[3-(1-adamantyl)-4hydroxyphenyl]-2-naphtalene carboxylic acid (AHPN/CD437) can effectively inhibit the growth and induce apoptosis of a wide variety of human malignant cell types including lung carcinoma, ${ }^{1-6}$ breast cancer, ${ }^{7-10}$ ovarian carcinoma, ${ }^{11}$ cervical carcinoma, ${ }^{12}$ prostate cancer, ${ }^{13}$ melanoma, ${ }^{14-16}$ neuroblastoma, ${ }^{17}$ and leukemia. ${ }^{18-20}$ Interestingly, CD437, unlike retinoic acid and most other synthetic retinoids which act via binding to and activation of specific nuclear receptors (RARs and RXRs), acts in an RAR-independent manner because it is effective in retinoic acid-resistant cells. ${ }^{1,18,19}$ RAR-deficient cells ${ }^{18}$ and in the presence of RAR antagonist. ${ }^{1,12,19}$ Thus, what is the authentic pathway for the action of CD437 remains to be investigated.

A number of apoptosis-related factors including caspases, ${ }^{4,19-21} \mathrm{P}^{2},^{4,5} \mathrm{P} 21,{ }^{3,5,7,18,22} \mathrm{P} 38,{ }^{23} \mathrm{Bcl}-2,{ }^{3,24} \mathrm{C}$ Myc, ${ }^{6} \mathrm{AP} 1,{ }^{15} \mathrm{C}$-jun ${ }^{3}$ and nur $77^{3}$ have been implicated in the CD437-induced growth arrest and apoptosis. However, the involvement of the individual factors was somehow inconsistent (variable) or even conflicting according to the experimental system used. ${ }^{1,12,25}$ Dual pathways (both dependent and independent) for some factors such as caspases and P53 in a given cell type have been reported. ${ }^{4,21,24}$ It was also observed in some cases that de novo protein synthesis was not required for the induction of apoptosis by CD437. ${ }^{19,26}$ Despite these findings, questions such as what is the primary target of CD437 and how the apoptotic factors could be activated by CD437, need to be answered.

Most recently, a study showed that CD437 could cause mitochondrial alterations that preceded other apoptotic manifestations in different cell models, including human myeloma cell line RPMI 8266, the RAR $\gamma$-negative myeloma cell line L363 and RPMI 8266 cytoplasts (anucleate cells). ${ }^{26}$ It was also found that purified mitochondria could be directly affected by CD437, and supernatants from 
CD437-treated mitochondria provoked chromatin condensation of isolated nuclei. ${ }^{26}$ On this basis, it was proposed that the rapid execution of CD437-induced apoptosis is a nucleus-independent phenomenon involving mitochondria.

Interestingly, several recent studies have demonstrated that the lysosomal aspartic protease cathepsin $D$ is involved in apoptosis. ${ }^{27-35}$ During apoptosis induced by certain factors such as oxidative stress, release of cathepsin D from lysosomes to the cytosol was found to precede mitochondrial alterations and other apoptotic manifestations. ${ }^{28,29,34-37}$ Inhibiting cathepsin $D$ with pepstatin A totally prevented the apoptosis. ${ }^{27-30,33-35}$ It was, therefore, suggested that lysosomal proteases, if released to the cytosol, might rapidly cause apoptosis directly by pro-caspase activation and/or indirectly by mitochondrial attack with ensuing discharge of pro-apoptotic factors. ${ }^{27-37}$ Thus, lysosomal rupture (leakage or destabilization) seems to be an early event and may play a pivotal role in apoptosis.

It is possible that CD437 can cause lysosomal leakage by itself or its oxidative metabolites and thereby rapidly induce apoptosis via mitochondrial attack independent of the nucleus. This study was designed to test this hypothesis by examining the roles of cathepsin $D$ and free radicals in CD437-induced apoptosis in human leukemia HL-60 cells.

\section{Results}

Exposure of HL-60 cells to CD437 $(1 \mu \mathrm{M})$ resulted in massive cell death within $6 \mathrm{~h}$. Morphologically, the CD437-treated cells exhibited nuclear pycnosis and fragmentation, cytoplasmic condensation, basophilia and apoptotic bodies (Figure 1). Staining with Annexin- $V$ showed that more than $30 \%$ of the cells underwent phosphatidylserine translocation (Figure 2). Measurement of mitochondrial transmembrane potential $\left(\Delta \psi_{\mathrm{m}}\right)$ indicated a loss of $\Delta \psi_{\mathrm{m}}$ in the CD437-treated cells (Figure 2). Furthermore, assay of caspase-3 activity showed a remarkable increase in the enzyme activity in the CD437treated cells (Figure 3 ). These apoptotic manifestations occurred apparently $4 \mathrm{~h}$ after CD437 exposure. The effective concentration of CD437 was as low as $0.25 \mu \mathrm{M}$ in HL-60 cells.

To explore the role of free radicals in the CD437-induced apoptosis, we determined the effect of $\alpha$-tocopherol acetate, an effective free radical scavenger, on the responses of HL-60 cells to CD437. As shown in Figures $1-3$, pretreatment of cells with $\alpha$-tocopherol acetate $(400 \mu \mathrm{M})$ significantly inhibited all the observed apoptotic alterations induced by CD437. Measurement of intracellular reactive oxygen species (ROS) levels by using the cellpermeant fluorescent probe $2^{\prime}, 7^{\prime}$-dichlorodihydrofluorescein diacetate indicated that treatment with CD437 resulted in a significantly high level of ROS, which could be attenuated by addition of $\alpha$-tocopherol acetate (Figure 4 ). These results suggest that free radicals play an important role in mediating CD437-induced apoptosis. The generation of free radicals seems to be an early event that precedes the apoptotic alterations, including mitochondrial change.

Previous studies have found that the lysosomal protease cathepsin D may act as a death mediator during

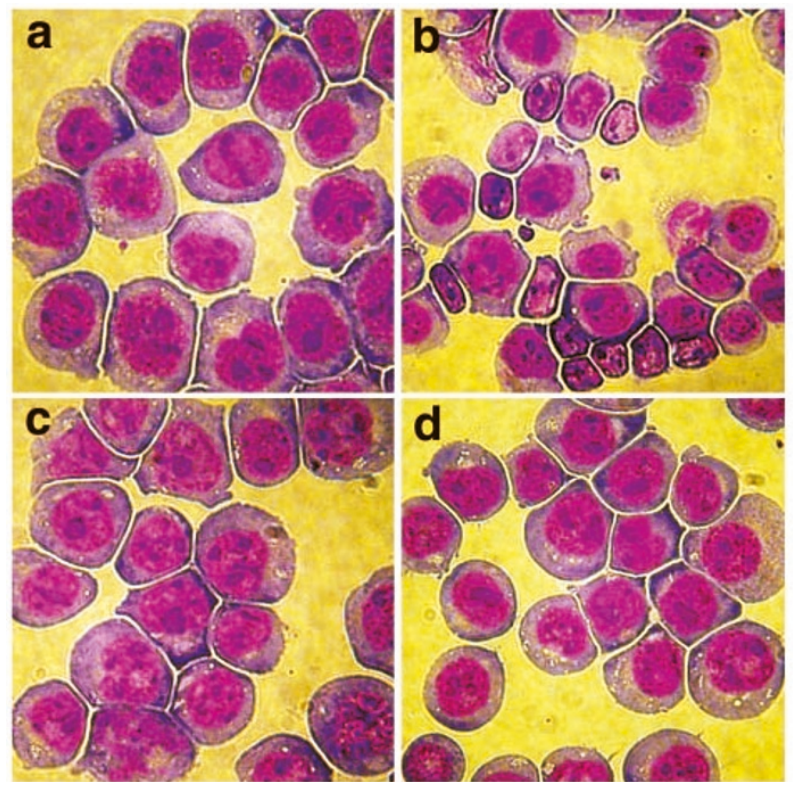

Figure 1 Morphological changes of HL60 cells after treatment with CD437 and the effects of antioxidants and cathepsin $D$ inhibitor. Cells were treated with vehicle/ethanol (a, control), $1 \mu \mathrm{M}$ of CD437 alone (b), CD437 $(1 \mu \mathrm{M})$ plus $400 \mu \mathrm{M}$ of antioxidant $\alpha$-tocopheryl acetate (c), or CD437 $(1 \mu \mathrm{M})$ plus $100 \mu \mathrm{M}$ of the cathepsin D inhibitor pepstatin A (d) for $6 \mathrm{~h}$, centrifuged onto slides, and stained with LeukoStat stain. Photographs were taken using a Nikon microscope

apoptosis. $^{27-37}$ Thus, we determined whether cathepsin $\mathrm{D}$ is involved in the CD437-induced apoptosis. As shown in Figures 1-4, pretreatment of HL60 cells with pepstatin A, a potent inhibitor of cathepsin $D$, effectively blocked the apoptotic effects of CD437. Surprisingly, pepstatin A also significantly inhibited the CD437-induced generation of free radicals (Figure 4). This suggests that cathepsin D exerts an apoptosis-initiating effect upstream of free-radical formation during the CD437-induced apoptosis.

Next, we tried to figure out whether the effect of cathepsin D is due to its overexpression in the CD437treated cells or its relocation/activation induced by CD437. To address this issue, Western blot analysis and immunofluorescence detection of cathepsin $D$ were performed. The results showed that there was no significant difference in any forms (precursor or active) of cathepsin D protein between control cells and CD437treated cells at different time points within $6 \mathrm{~h}$ (data not shown). This suggests that expression and/or conversion (activation) of cathepsin $D$ is not involved during the period of time. However, immunofluorescence staining of cathepsin $D$ revealed different patterns of intracellular distribution of cathepsin $D$ between control cells and CD437-treated cells (Figure 5). Control cells displayed a distinct granular staining, whereas CD437-treated cells exhibited more diffuse staining. This pattern corresponds to release of the enzyme from lysosomes to the cytosol, as demonstrated by others using electron microscopy in different cell types. ${ }^{29,34,35}$ This phenomenon of cathepsin $D$ relocation could be observed as early as $30 \mathrm{~min}$ after exposure to CD437 and prior to apparent apoptotic 

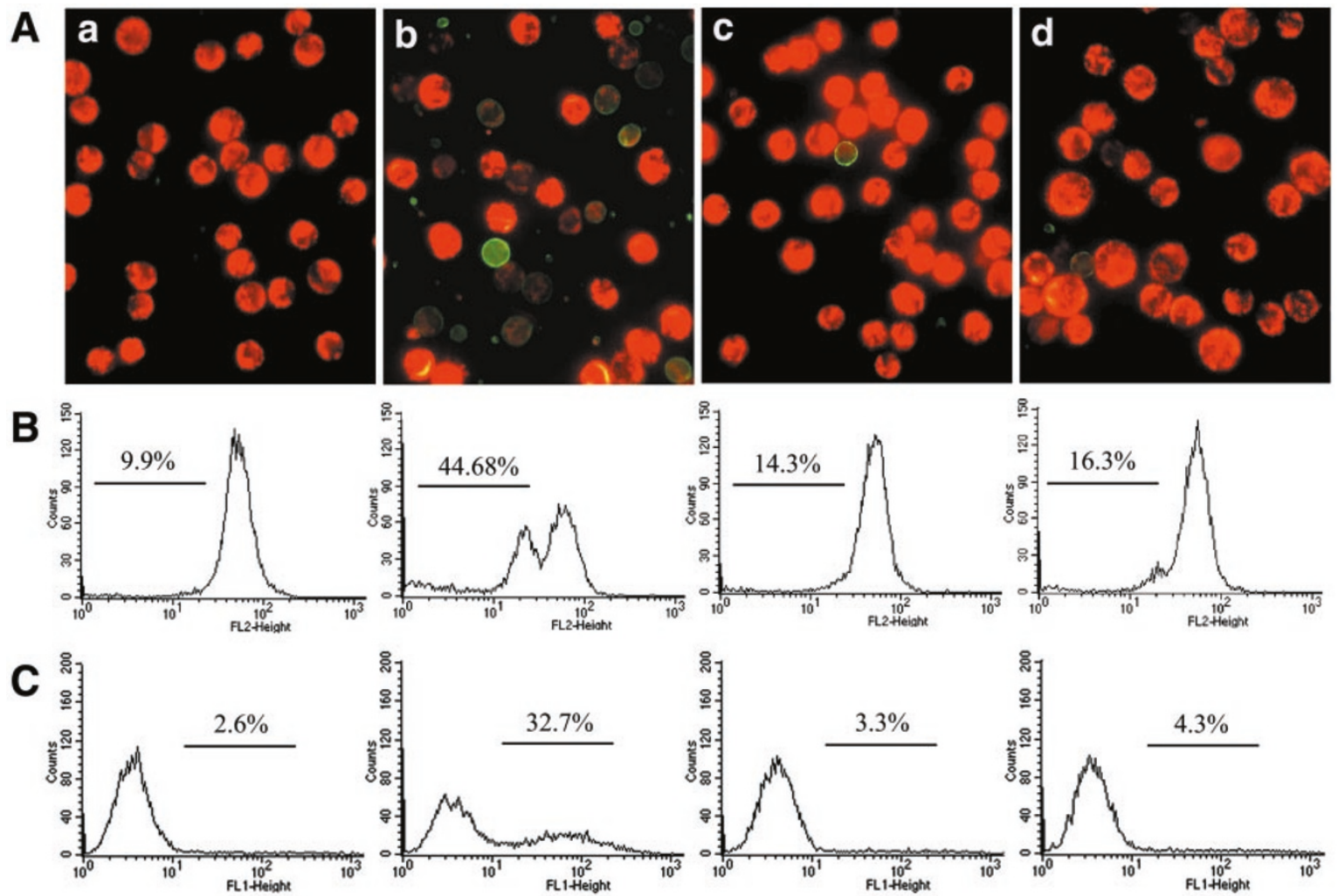

Figure 2 Mitochondrial alterations and phosphatidylserine exposure of HL60 cells in response to different treatments. Cells were treated with vehicle/ethanol (a,

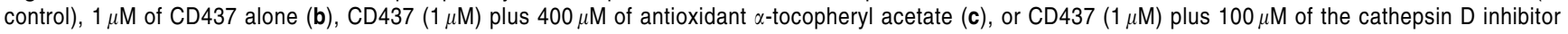
pepstatin A (d) for $6 \mathrm{~h}$. Cells were then co-stained with MitoTracker-Red (Molecular Probes) to detect changes in inner mitochondrial transmembrane potential $\left(\Delta \psi_{\mathrm{m}}\right)$ and FITC-ApoAlert Annexin V (Clonetech) to detect cell surface phosphatidylserine (PS). The stained cells were analyzed by fluorescence microscopy (A; red, mitochondria stained with MitoTrack; green, PS stained with annexin V) and by flow cytometry (B, mitochondria staining; C, PS staining)

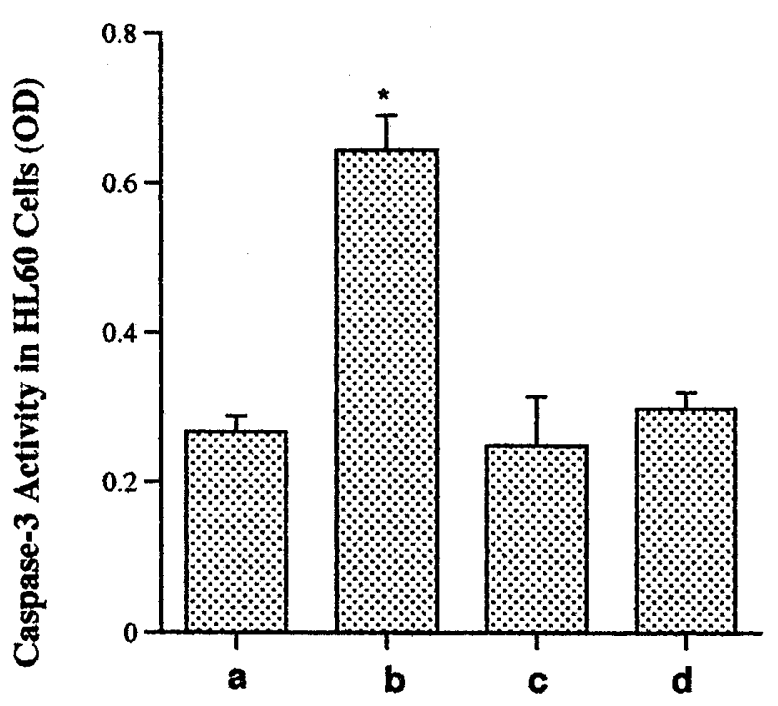

Figure 3 Caspase-3 activity in HL60 cells following different treatments. Cells were treated with vehicle/ethanol (a, control), $1 \mu \mathrm{M}$ of CD437 alone (b), CD437 $(1 \mu \mathrm{M})$ plus $400 \mu \mathrm{M}$ of antioxidant $\alpha$-tocopheryl acetate (c), or CD437 $(1 \mu \mathrm{M})$ plus $100 \mu \mathrm{M}$ of the cathepsin D inhibitor pepstatin $\mathrm{A}$ (d) for $6 \mathrm{~h}$. Caspase- 3 activity was determined as described in Materials and Methods. The values are the mean \pm S.D. of three independent experiments $\left(n=3,{ }^{*}\right.$ represents $P<0.05$ vs control)
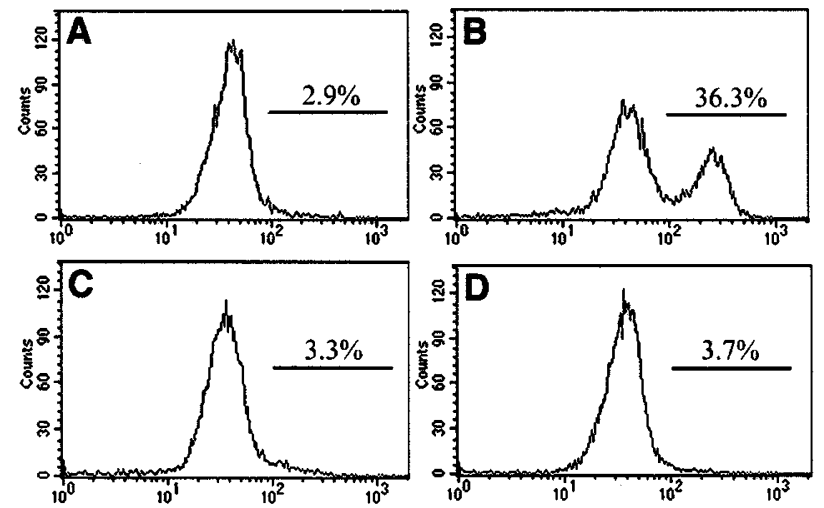

Figure 4 Generation of free radicals (reactive oxygen species, ROS) in HL60 cells after treatment with CD437. Cellular oxidative activity was measured by flow cytomestry using $2^{\prime}, 7^{\prime}$-dichlorodihydrofluorescein diacetate as probe. Intracellular levels of ROS rose $30 \mathrm{~min}$ after exposure to $1 \mu \mathrm{M} \mathrm{CD} 437$ (B; A, control). Pretreatment of cells with $400 \mu \mathrm{M} \alpha$-tocopheryl acetate (C), or $100 \mu \mathrm{M}$ pepstatin A (D) prevented the CD437-induced generation of free radicals

alterations. Interestingly, neither $\alpha$-tocopherol acetate nor pepstatin A could inhibit the CD437-induced relocation of cathepsin D, although both of them could effectively prevent the CD437-induced apoptosis, suggesting that the 

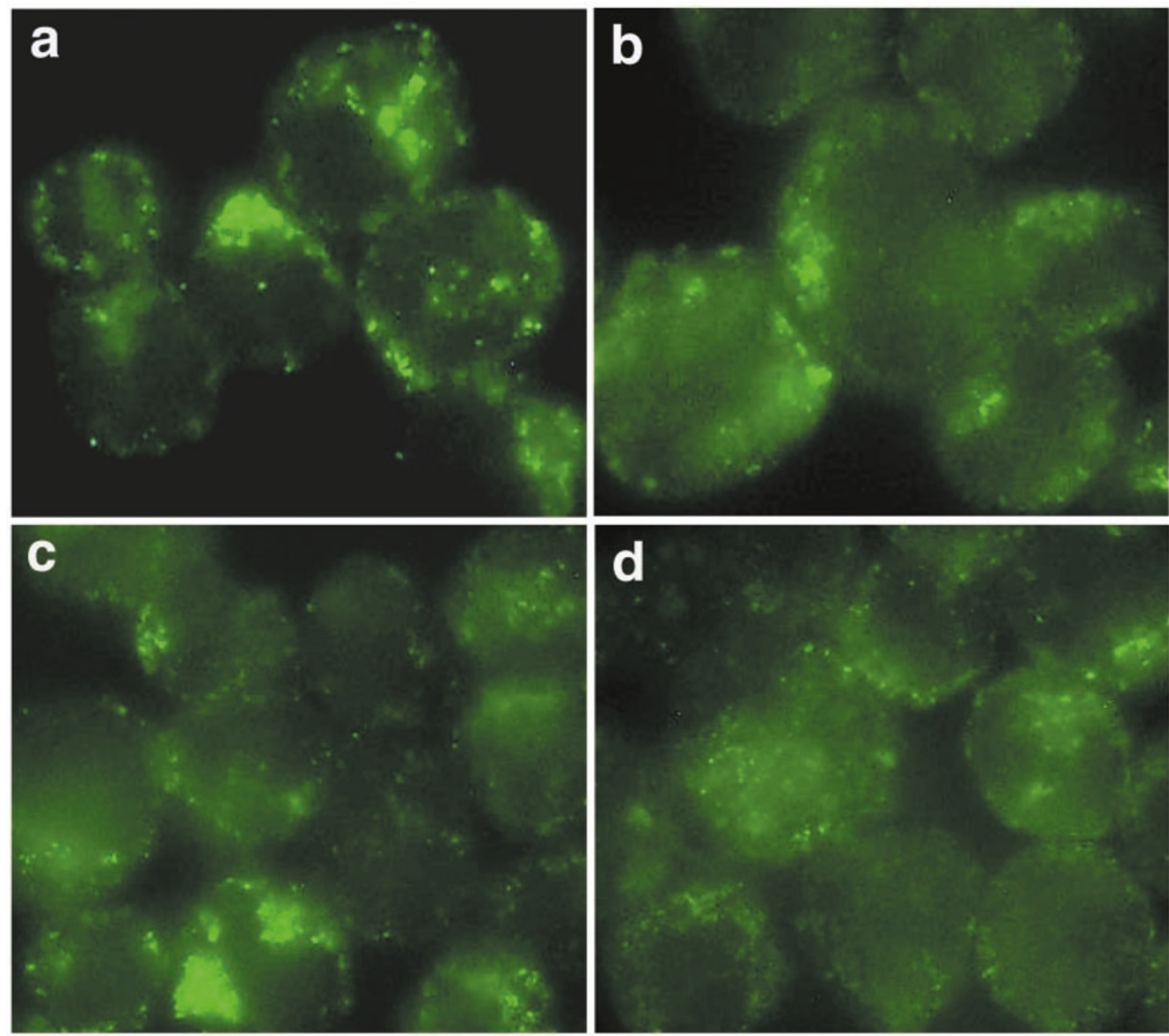

Figure 5 Immunofluorescence detection of cathepsin D in HL60 cells following different treatments for $4 \mathrm{~h}$. (a) control cells (treated with vehicle). (b) cells treated with $1 \mu \mathrm{M}$ CD437. (c) cells pretreated with $400 \mu \mathrm{M} \alpha$-tocopheryl acetate and exposed to CD437. (d) cells pretreated with $100 \mu \mathrm{M}$ pepstatin A and exposed to CD437. Note granular staining in control cells (a) and diffuse staining in CD437-treated cells (b). Both $\alpha$-tocopheryl acetate and pepstatin A failed to block the CD437induced changes

release of cathepsin $D$ is an early event underlying the apoptosis induced by CD437.

In light of the CD437-induced release of cathepsin D, we further examined the effect of CD437 on lysosomal membrane stability using neutral red as a lysosomotropic probe. Cells were preloaded with neutral red, challenged with CD437 and then the distribution of neutral red dye was examined with microscopy. As shown in Figure 6, neutral red dye was concentrated in lysosomes in a granular pattern with intense red stain in control cells, whereas a redistribution of the dye, as shown by a diffuse or fade-stain pattern, was observed in the CD437-treated cells. The time course of this effect indicated that the phenomena could take place within 30 min following CD437 exposure (not shown). The redistribution of the lysosomal probe could not be blocked by either $\alpha$ tocopherol acetate or pepstatin $A$, but the apoptotic changes in morphology could be effectively prevented by both of them (Figure 6). Use of another lysosomotropic probe, acridine orange, obtained similar results (data not shown). Obviously, these effects on the distribution of lysosomotropic probes were parallel to those effects on the distribution of cathepsin D. These findings suggest that
CD437 may act as a lysosomal destabilizer to induce lysosomal leak.

Finally, to see whether the nuclear retinoic acid receptors (RARs) are involved in the CD437-induced apoptosis, cell death in response to CD437 was examined in the presence of the RAR antagonist AGN 193109 or in the RAR-deficient HL-60R cells. Our results showed that CD437 was still effective in induction of apoptosis in $\mathrm{HL}$ $60 \mathrm{R}$ cells, and the RAR antagonist failed to block the apoptotic effects of CD437 (data not shown), suggesting that the action of CD437 is RAR-independent. In addition, our previous studies have shown that the mannose 6phosphate/insulin-like growth factor-Il receptor (M6P/ IGF2R) mediate the apoptotic effect of certain retinoids. $^{38,39}$ To test whether the CD437-induced apoptosis is mediated by the M6P/IGF2R, we examined the apoptotic effect of CD437 in M6P/IGF2R-positive and M6P/IGF2Rnegative P388D1 cells. We found that CD437 was still effective in the M6P/IGF2R-negative cells but the receptornegative cells seemed to be less sensitive to CD437 than the receptor-positive cells (data not shown), suggesting that the M6P/IGF2R is not essential for the action of CD437 but may potentiate its effect. Similarly, the CD437-induced 

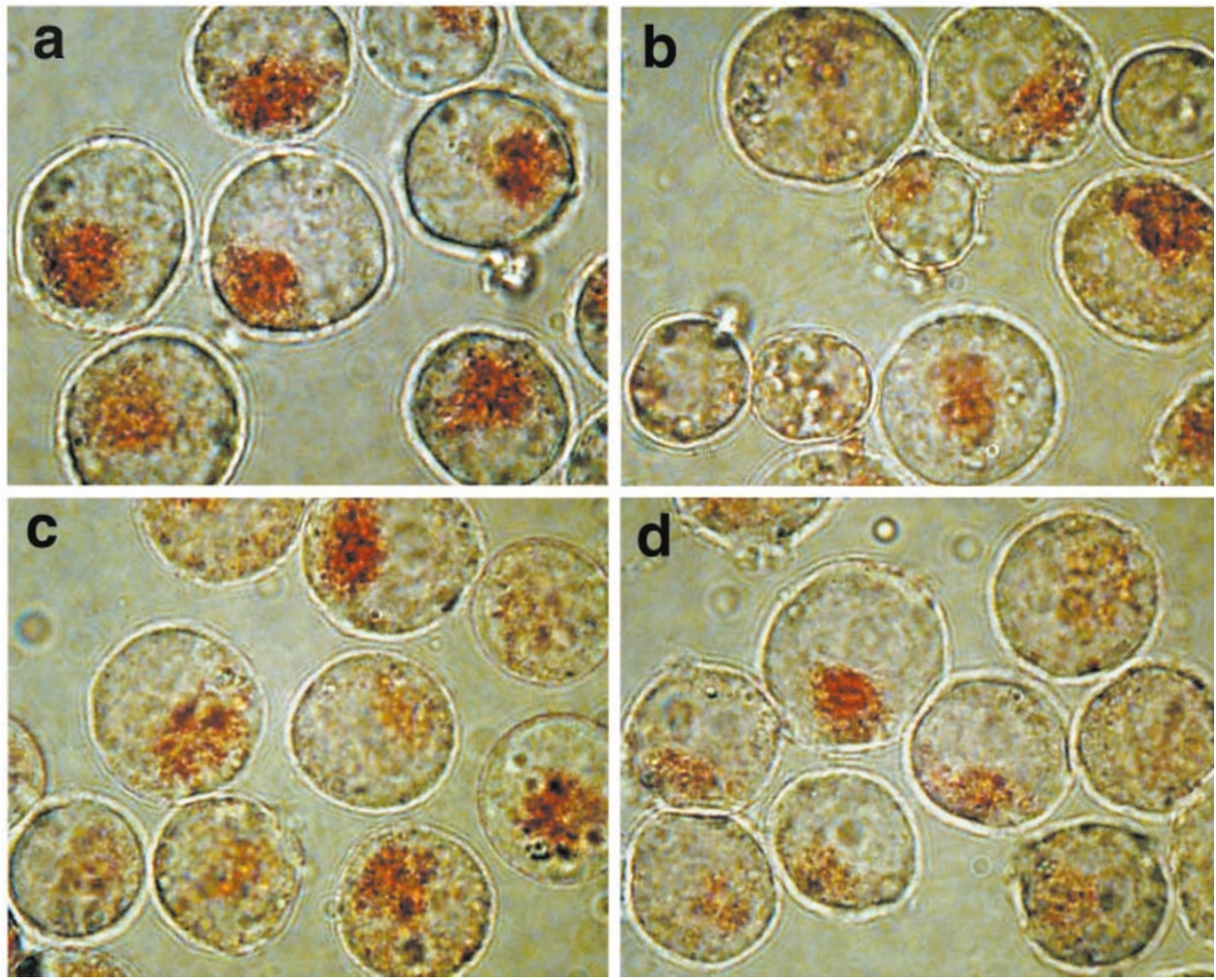

Figure 6 Lysosomal leakage induced by CD437 in HL60 cells. Cells were preloaded with the lysosomal probe neutral red, exposed to $1 \mu \mathrm{M} \mathrm{CD} 437$ for $6 \mathrm{~h}$ and then the distribution of neutral red dye was examined using a light microscope. (a) control cells (treated with vehicle). (b) cells treated with $1 \mu \mathrm{M}$ CD437. (c) cells pretreated with $400 \mu \mathrm{M}$-tocopheryl acetate and exposed to CD437. (d) cells pretreated with $100 \mu \mathrm{M}$ pepstatin A and exposed to CD437. Note a granular pattern with intense red stain in control cells (a) and a diffuse or fade-stain (pale) pattern in CD437-treated cells (b). The redistribution of the lysosomal probe could not be blocked by either $\alpha$-tocopherol acetate or pepstatin A but the apoptotic changes in morphology could be effectively prevented by both of them (c and $\mathbf{d}$ )

apoptosis of P388D1 cells could be inhibited by pepstatin $A$, suggesting the involvement of cathepsin $D$.

\section{Discussion}

In the present study, we have examined the mechanism by which CD437 induces apoptosis in HL-60 cells. We found that cathepsin $\mathrm{D}$ and free radicals play a pivotal role in mediating the CD437-induced apoptosis. The data presented here demonstrate that CD437 may trigger apoptosis through a direct attack on lysosomes.

Based on our findings, we propose a coherent pathway for CD437-induced apoptosis in HL-60 cells, as illustrated in Figure 7. The sequence of events (steps) of the pathway is as follows: (1) CD437 targets primarily on lysosomes and induces lysosomal leakage or rupture. CD437 is a hydrophobic (lipid-solvable) compound capable of penetrating and partitioning into lipid membrane of cellular organelles including lysosomes. Thus, it is not impossible for CD437 to rapidly alter or disturb lysosomal membrane stability or permeability. This is supported by our findings that CD437 could induce relocation/release of cathepsin D, a lysosomal marker enzyme, as well as neutral red, a lysosomotropic dye (Figures 5 and 6). This event took place as early as $30 \mathrm{~min}$ following exposure to CD437 and prior to free radical formation and other apoptotic alterations. (2) Cathepsin D, once released from lysosomes to the cytosol, may convert certain (unknown) substances to bioactive molecules such as free radicals, directly attack other cellular organelles (e.g., mitochondria) or directly activate caspases. Indeed, our results showed that CD437 treatment resulted in a rapid rise in intracellular free radicals, and addition of free radical scavenger could block all apoptotic alterations, including mitochondrial changes, but failed to inhibit the cathepsin $D$ relocation, whereas cathepsin $D$ inhibitor could block both free radical formation and apoptosis (Figure 4). This suggests that the free radical generation takes place before all other apoptotic alterations but secondary to cathepsin D release. Thus, cathepsin $D$ seems to act as a death initiator in this system. (3) Mitochondria undergoes alterations as a result of attack of cathepsin D and/or free radicals. Mitochondrial alteration has been well recognized as a typical manifestation of apoptosis in many systems ${ }^{40}$ and has been recently shown to be an underlying mechanism of CD437-induced apoptosis in human myeloma cell lines. ${ }^{26}$ In the present study, we found that exposure of cells to CD437 resulted in loss of mitochondrial transmembrane potential, which could be blocked by either the inhibitor of cathepsin $D$ or free radical scavenger. This supports the notion that the mitochondrial alteration in this case is secondary to the effect of cathepsin $D$ and/or free 


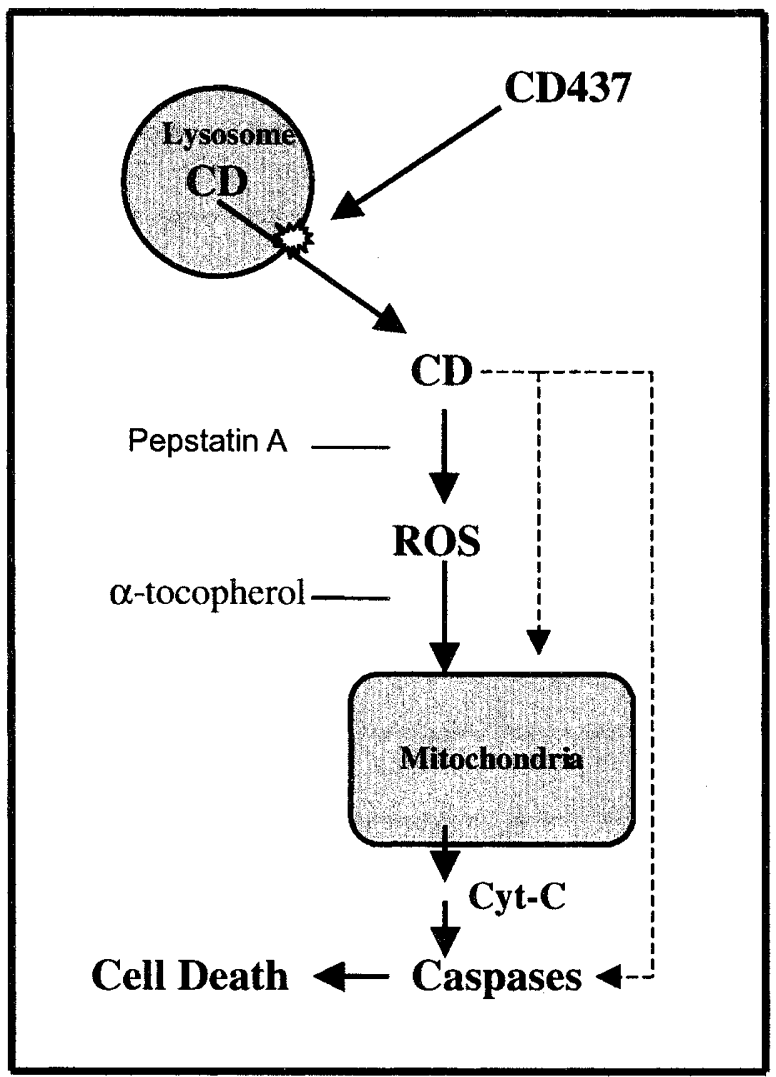

Figure 7 Model of a possible lysosomal pathway for CD437-induced apoptosis. CD437 may target directly on lysosomes and induces lysosomal leakage or partial rupture, leading to release of cathepsin $D(C D)$ from lysosomes to the cytosol. Released cathepsin D may convert certain unknown substances to bioactive molecules such as free radicals which may attack other cellular organelles (e.g., mitochondria, nucleus). In addition, cathepsin D may directly attack the organelles or activate caspases. As a result of attack of cathepsin $D$ and/or free radicals, mitochondria may undergo apoptotic alterations. Thus, apoptotic factors (e.g., cytochrome C, caspases) are released or activated and execute apoptosis

radicals. (4) Apoptotic factors (e.g., caspases) are released or activated and execute apoptosis. Following mitochondrial alteration, certain factors such as cytochrome-C may be discharged and then trigger expression or activation of other apoptotic factors such as caspase-3, an executor of apoptosis. In this study, an enhanced level of caspase-3 activity was observed in the CD437-treated cells. This suggests that caspase- 3 is involved in the CD437-induced apoptosis, consistent with the findings of previous studies. $^{4,19-21}$

Nevertheless, it is possible that CD437 is a free-radicalgenerating compound. The active form of CD437 is its oxidative metabolites that can directly attack lysosomes and mitochondria. If this is the case, free radical-scavenger should be able to inhibit all the CD437-induced changes. However, our findings do not support this possibility because the free radical-scavenger $\alpha$-tocopherol failed to block the CD437-induced cathepsin D release, and the CD437-induced rise in free radicals could be effectively attenuated by the cathepsin $D$ inhibitor pepstatin $A$, which is not a free-radical scavenger. ${ }^{34}$ Nevertheless, our findings do not exclude the possibility that multiple pathways may be involved.

Lysosomes, as an acidic compartment with limiting membranes, are the major site for cellular catabolism and contain a wide spectrum of hydrolytic enzymes (e.g. proteases, nucleases, etc.) that can degrade nearly all cellular components. Among the most powerful hydrolytic enzymes are the cathepsins. The lysosomal cathepsins, particularly cathepsin $D$, the major intracellular aspartic protease present in relatively high concentrations within the lysosomes, have been demonstrated to be involved in apoptosis by several recent studies in different systems. $^{27-35}$ In this context, it is conceivable that an uncontrolled leakage of the enzymes from lysosomes to the cytosol may be dangerous or even lethal for cells. Indeed, our data presented here and those reported by others previously. ${ }^{28,29,34-37}$ have demonstrated that lysosomal leakage or partial rupture, leading to release of cathepsin $D$, plays an important, perhaps even initiating, role in apoptosis. These findings, therefore, provide new insights into the mechanisms of apoptosis and challenge the early notion that lysosomal rupture is connected solely with cellular necrosis, and the essential functions of cathepsin D is limited to bulk degradation of proteins in lysosomes. It is now evident that lysosomes may function as suicide bags and therefore are the potential target for induction of apoptosis, whereas cathepsin D may be a key mediator or executor of apoptosis. Thus, any agents that are able to alter lysosomal membrane stability may serve as inducers of apoptosis.

Because lysomomal proteases serve as mediators or executors of apoptosis in the lysosomal pathway, any factors or processes that determine the bioavailabilty of the enzymes in lysosomes may affect the lysosomal apoptosis. Normally, trafficking of newly synthesized lysosomal enzymes from the TGN to lysosomes are carried out by two kinds of mannose 6-phosphate receptors (cation dependent and cation-independent). ${ }^{41}$ Thus, quantity and functional activity of the receptors in a cell may have an effect on the sensitivity of the cell to apoptosis using the lysosomal pathway. Our results that CIMPR-deficient cells were relatively less sensitive to CD437 supports this hypothesis.

In conclusion, we have demonstrated a lysosomal pathway for apoptosis induced by CD437 in HL-60 cells. In this pathway, CD437 acts as a lysosomal destabilizer to cause release of cathepsin $D$, which serves as a death mediator.

\section{Materials and Methods}

\section{Materials}

CD437 (AGN 192837) and the nuclear retinoic acid receptor (RARs) antagonist AGN193109 were synthesized by Allergan (Irvine, CA, USA). Retinoids were dissolved in ethanol at an initial stock concentration of $10 \mathrm{mM}$ and stored at $-20^{\circ} \mathrm{C}$ in the dark. Pepstatin A and a-tocopheryl acetate were obtained from Sigma (St. Louis, MO, 
USA). Annexin V-EGFP Apoptosis kit and the Caspase-3 Colorimetric Assay kit were purchased from Clontech (Palo Alto, CA, USA). MatoTracker, 2',7'-dichlorodihydrofluorescein diacetate $\left(\mathrm{H}_{2} \mathrm{DCFDA}\right)$ and the neutral red were purchased from Molecular Probes, Inc (Eugene, OR, USA). The mouse anti-human-cathepsin D monoclonal antibody was obtained from Zymed Laboratories Inc. (Carlton Court, CA, USA). The goat anti-mouse IgG conjugated-HRP and the goat anti-mouse IgG conjugated-FITC polyclonal antibody were obtained from Jackson Immuno Research Laboratories Inc (West Grove, PA, USA). The ECL Western blotting system was obtained from NEN Life Science (Boston, MA, USA). RPMI 1640 medium and fetal bovine serum (FBS) were obtained from Cellgro and JRH Biosciences (Leneta, KS, USA), respectively.

\section{Cell lines and culture conditions}

The human leukemia cells, HL-60 (CCL-240 American Type Culture Collection) and HL-60R (kindly provided by Dr. SJ Collins, Fred Hutchinson Cancer Research Center) were maintained in RPMI 1640 medium supplemented with $10 \%$ fetal bovine serum, without antibiotics. The cells were incubated in humidified air with $5 \% \mathrm{CO}_{2}$ at $37^{\circ} \mathrm{C}$ and subcultured every 3 days.

\section{Induction and assessment of apoptosis}

To induce apoptosis, cells were grown on 12-well plates at $10^{6} / \mathrm{ml}$ and treated with $1 \mu \mathrm{M}$ of $\mathrm{CD} 437$ at $37^{\circ} \mathrm{C}$ for $1-6 \mathrm{~h}$ alone or in combination with the antioxidant $\alpha$-tocopheryl acetate $(400 \mu \mathrm{M})$, or the cathepsin $\mathrm{D}$ inhibitor pepstatin $\mathrm{A}(100 \mu \mathrm{M})$. The concentration of $\alpha$-tocopheryl acetate or pepstatin A alone had no effect on the growth of cells. Apoptotic morphology was detected with a light microscope following cytospin and staining with LeukoStat stain (Fisher). Cells were scored as apoptotic if there was evidence of nuclear pycnosis and fragmentation, cytoplasmic condensation, apoptotic bodies and basophilia. The annexin $\mathrm{V}$ cell surface labeling was also carried out according to the manufacturer's instruction using the ApoAlert Annexin V Apoptosis Kit (Clonetech). Briefly, cells were washed with cold PBS, resuspended in $200 \mu \mathrm{l}$ of binding buffer, and incubated with $50 \mu \mathrm{l}$ of Annexin V-EGFP and $10 \mu \mathrm{l}$ of PI for $10 \mathrm{~min}$ in the dark. The cells were mounted on glass slides and photographed with a Nikon photomicroscope. The percentage of apoptotic cells was quantified by flow cytometry.

\section{Assessment of lysosomal stability}

To detect lysosomal stability, neutral red, a common lysosomal probe, was used. HL60 cells were loaded with $10 \mu \mathrm{g} / \mathrm{ml}$ neutral red in RPMI1640 medium at $37^{\circ} \mathrm{C}, 5 \% \mathrm{CO}_{2}$ for $2 \mathrm{~h}$. Then, cells following pelleting were resuspended in RPMI 1640 medium with ethanol (control), CD437 alone or CD437 plus $\alpha$-tocopheryl or pepstatin A and incubated at $37^{\circ} \mathrm{C}$ for $30 \mathrm{~min}$. The cells were gently pelleted and mounted on glass slides and photographed by light microscope.

\section{Detection of cathepsin D by immunocytochemistry and immunoblot}

For immunocytochemistry, HL-60 cells were fixed in $4 \%$ paraformaldehyde in phosphate-buffered saline (PBS) for $30 \mathrm{~min}$ at $4{ }^{\circ} \mathrm{C}$ followed by exposure to $1 \mu \mathrm{M}$ of CD437 for $0.5,1,2,4$ or $6 \mathrm{~h}$ and then processed for immunostaining. Briefly, the cells were incubated with a monoclonal mouse-antihuman cathepsin $D$ antibody (dilution, $1: 5$ ) at $0^{\circ} \mathrm{C}$ for $1 \mathrm{~h}$, followed by a goat anti-mouse IgG-FITC conjugate $(1: 2000)$ after washing three times in PBS. Thereafter the cells were rinsed in PBS three times again, mounted in antifade reagent (Molecular Probes), and examined and photographed in a Nikon photomicroscope. For Western blot, the extracts from HL-60 cells cultured with or without $1 \mu \mathrm{M}$ of CD437 were obtained by the treatment with cell lysis buffer containing $150 \mathrm{mM} \mathrm{NaCl}, 50 \mathrm{mM}$ Tris, $5 \mathrm{mM}$ EDTA and $0.5 \% \mathrm{NP}-40$, including the protease inhibitor containing $0.01 \mathrm{mg} / \mathrm{ml}$ leupeptin, $0.01 \mathrm{mg} / \mathrm{ml}$ pepstatin, $0.1 \mathrm{mM}$ PMSF. Ten $\mu \mathrm{g}$ of proteins from each sample was subjected to $12 \%$ SDS-polyacrylamide gel electrophorosis (SDS-PAGE) and subsequently transferred to PVDF membrane (Immunobilon, Millipore, USA). The blots were incubated with anti-cathepsin D monoclonal antibody (dilution 1:50) and visualized with the ECL detection system (NEN Life Science, USA). Quantitation analysis of the immunosignals was carried out using Scanning Imager.

\section{Assessment of mitochondrial transmembrane potential $\left(\Delta \psi_{\mathrm{m}}\right)$}

Changes in inner mitochondrial transmembrane potential $\left(\Delta \psi_{\mathrm{m}}\right)$ in $\mathrm{HL}$ 60 and HL-60R cells following different treatments were examined by flow cytometry and photographed in a Nikon photomicroscope using MitoTracker (Molecular Probes) as probes. In detail, $1 \mathrm{mM}$ of MitoTracker stock solution was made up in dimethyl sulfoxide and then $300 \mathrm{nM}$ MitoTrack working solution was prepared freshly by diluting stock solution in RPMI 1640 medium and was subsequently added to the plates with HL60 or HL60R cells. The cells were kept at $37^{\circ} \mathrm{C}$ for $30 \mathrm{~min}$ in the dark. After incubation, cells were rinsed twice in PBS and resuspended in $1 \mathrm{ml}$ of PBS for measurement of the fluorescence by FACScan, or mounted on glass slides for photograph in a Nikon photomicroscope.

\section{Measurement of intracellular ROS levels}

To monitor intracellular oxidative activity, the cell-permeant probe 2',7'-dichlorodihydrofluorescein diacetate $\left(\mathrm{H}_{2} \mathrm{DCFDA}\right)$ (Molecular Probes) was used. The oxidative activity of HL60 and HL60R cells were assessed following the different treatments. Briefly, the cells were centrifuged, washed twice with PBS and resuspended in RPMI 1640 medium with $5 \mu \mathrm{M} \mathrm{H} \mathrm{H}_{2}$ DCFDA for $30 \mathrm{~min}$ at $37^{\circ} \mathrm{C}$. After the incubation, cells were washed again two times with PBS and resuspended in $1 \mathrm{ml}$ of PBS. The fluorescence was measured with $\lambda_{\mathrm{ex}}=488 \mathrm{~nm}$ and $\lambda_{\mathrm{em}}=575 \mathrm{~nm}$ by FACS assay.

\section{Measurement of Caspase-3 enzyme activity}

Caspase-3 activity was measured using the Caspase-3 Colorimetric Assay Kit (Clontech) according to the manufacture's protocol. In brief, $2 \times 10^{6} \mathrm{ml}$ cells were lysed with $50 \mu$ l of chilled cell lysis buffer. The clear supernatant was obtained by microcentrifugation for $10 \mathrm{~min}$ at 12000 r.p.m./min and used for caspase-3 colorimetric protease assay. The protein $(200 \mu \mathrm{g})$ was mixed with $50 \mu \mathrm{l}$ of $2 \times$ recation buffer (containing $10 \mathrm{mM} \mathrm{DTT)}$ and $5 \mu \mathrm{l}$ of caspase-3 substrate. After incubation at $37^{\circ} \mathrm{C}$ for $1 \mathrm{~h}$, samples were read at $400 \mathrm{~nm}$ by a spectrophotometer.

\section{Acknowledgments}

We thank Dr. SJ Collins for HL-60R cells. We are grateful to Dr. Alexander Leaf for his support and encouragement. This work was supported by National Cancer Institute Grant CA-79553 (to JX Kang). 


\section{References}

1. Sun SY, Yue P, Shroot B, Hong WK and Lotan R (1997) Induction of apoptosis in human non-small cell lung carcinoma cells by the novel synthetic retinoid CD437. J. Cell. Physiol. 173: 279-284

2. Adachi H, Preston G, Harvat B, Dawson Ml and Jetten AM (1998) Inhibition of cell proliferation and induction of apoptosis by the retinoid AHPN in human lung carcinoma cells. Am. J. Respir. Cell. Mol. Biol. 18: 323-333

3. LiY, Lin B, Agadir A, Liu R, Dawson MI, Reed JC, Fontana JA, BostF, Hobbs PD, Zheng Y, Chen GQ, Shroot B, Mercola D and Zhang XK (1998) Molecular determinants of AHPN (CD437)-induced growth arrest and apoptosis in human lung cancer cell lines. Mol. Cell. Biol. 18: 4719-4731

4. Sun SY, Yue P, Wu GS, El-Deiry WS, Shroot B, Hong WK and Lotan R. (1999) Mechanisms of apoptosis induced by the synthetic retinoid CD437 in human nonsmall cell lung carcinoma cells. Oncogene 18: 2357-2365

5. Sun SY, Yue P, Wu GS, El-Deiry WS, Shroot B, Hong WK and Lotan R (1999) Implication of p53 in growth arrest and apoptosis induced by the synthetic retinoid CD437 in human lung cancer cells. Cancer Res. 59: 2829-2833

6. Sun SY, Yue P, Shroot B, Hong WK and Lotan R (1999) Implication of c-Myc in apoptosis induced by the retinoid CD437 in human lung carcinoma cells. Oncogene 18: 3894-2901

7. Li XS, Rishi AK, Shao ZM, Dawson MI, Jong L, Shroot B, Reichert U, Ordonez J and Fontana JA (1996) Posttranscriptional regulation of p21WAF1/CIP1 expression in human breast Carcinoma cells. Cancer Res. 56: 5055-5062

8. Widschwendter M, Daxenbichler G, Culig Z, Michel S, Zeimet AG, Mortl MG, Widschwendter A and Marth C (1997) Activity of retinoic acid receptor-gamma selectively binding retinoids alone and in combination with interferon-gamma in breast cancer cell lines. Int. J. Cancer 71: 497-504

9. Rishi AK, Sun RJ, Gao Y, Hsu CK, Gerald TM, Sheikh MS, Dawson MI, Reichert U, Shroot B, Jr AJ, Brewer G and Fontana JA (1999) Post-transcriptional regulation of the DNA damage-inducible gadd45 gene in human breast carcinoma cells exposed to a novel retinoid CD437. Nucleic Acids Res. 27: 3111-3119

10. Hsu CK, Rishi AK, LiXS, Dawson MI, ReichertU, ShrootBand FontanaJA(1997) $\mathrm{Bcl}-\mathrm{X}(\mathrm{L})$ expression and its downregulation by a novel retinoid in breast carcinoma cells. Exp. Cell. Res. 232: 17-24

11. Langdon SP, Rabiasz GJ, Ritchie AA, Reichert U, Buchan P, Miller WR and Smyth JF (1998) Growth-inhibitory effects of the synthetic retinoid CD437 against ovarian carcinoma models in vitro and in vivo. Cancer Chemother Pharmacol. 42: 429-432

12. Oridate N, Higuchi M, Suzuki S, Shroot B, Hong WK and Lotan R (1997) Rapid induction of apoptosis in human C33A cervical carcinoma cells by the synthetic retinoid 6-[3-(1-adamantyl hydroxyphenyl]-2-naphtalene carboxylic acid (CD437). Int. J. Cancer 70: 484-487

13. Liang JY, Fontana JA, Rao JN, Ordonez JV, Dawson MI, Shroot B, Wilber JF and Fen $P$ (1999) Synthetic retinoid CD437 induces S-phase arrest and apoptosis in human prostate cancer cells LNCaP and PC-3. Prostate 15;38: 228-236

14. Schadendorf D, Worm M, Jurgovsky K, Dippel E, Reichert U and Czarnetzki BM (1995) Effects of various synthetic retinoids on proliferation and immunophenotype of human melanoma cells in vitro. Recent Results Cancer Res. 139: 183193

15. Schadendorf D, Kern MA, Artuc M, Pahl HL, Rosenbach T, Fichtner I, Nurnberg W, Stuting S, von StebutE, Worm M, Makki A, Jurgovsky K, Kolde G and HenzBM (1999) Treatment of melanoma cells with the synthetic retinoid CD437 induces apoptosis via activation of AP-1 in vitro, and causes growth inhibition in xenografts in vivo. J. Cell. Biol. 135: 1889-1898

16. Danielsson C, Torma H, Vahlquist A and Carlberg C (1999) Positive and negative interaction of 1,25-dihydroxyvitamin $\mathrm{D} 3$ and the retinoid CD 437 in the induction of human melanoma cell apoptosis. Int. J. Cancer. 81: 467-470

17. Meister B, Fink FM, Hittmair A, Marth C and Widschwendter M (1998) Antiproliferative activity and apoptosis induced by retinoic acid receptor-gamma selectively binding retinoids in neuroblastoma. Anticancer Res. 18: 1777-1786

18. Hsu CA, Rishi AK, Su-LiX, Gerald TM, Dawson MI, Schiffer C, ReichertU, Shroot B, Poirer GC and Fontana JA (1997) Retinoid induced apoptosis in leukemia cells through a retinoic acid nuclear receptor-independent pathway. Blood 89:4470 4479
19. Mologni L, Ponzanelli I, Bresciani F, Sardiello G, Bergamaschi D, Gianni M, Reichert U, Rambaldi A, Terao M and Garattini E (1999) The novel synthetic retinoid 6-[3-adamantyl-4-hydroxyphenyl]-2-naphthalene carboxylic acid (CD437) causes apoptosis in acute promyelocytic leukemia cells through rapid activation of caspases. Blood 93: 1045-1061

20. Gianni M and de The H (1999) In acute promyelocytic leukemia NB4 cells, the synthetic retinoid CD437 induces contemporaneously apoptosis, a caspase-3mediated degradation of PML/RARalpha protein and the PML retargeting on PML-nuclear bodies. Leukemia 13: 739-749

21. Adachi H, Adams A, Hughes FM, Zhang J, Cidlowski JA and Jetten AM (1998) Induction of apoptosis by the novel retinoid AHPN in human T-cell lymphoma cells involves caspase-dependent and independent pathways. Cell Death Differ. 5: $973-983$

22. Zhang Y, Rishi AK, Dawson MI, Tschang R, Farhana L, Boyanapalli M, Reichert U, Shroot B, Van Buren EC and Fontana JA (2000) S-phase arrest and apoptosis induced in normal mammary epithelial cells by a novel retinoid. Cancer Res. 60 : 2025-2032

23. Zhang Y, Huang Y, Rishi AK, Sheikh MS, Shroot B, ReichertU, Dawson M, Poirer Gand Fontana JA (1999) Activation of the p38 and JNK/SAPK mitogen-activated protein kinase pathways during apoptosis is mediated by a novel retinoid. Exp. Cell. Res. 247: 233-240

24. Hsu SL, Yin SC, Liu MC, Reichert U and Ho WL (1999) Involvement of cyclindependent kinase activities in CD437-induced apoptosis. Exp. Cell. Res. 252: 332-341

25. Fontana JA, Sun RJ, Rishi AK, Dawson MI, Ordonez JV, Zhang Y, Tschang SH, Bhalla K, Han Z, Wyche J, Poirer G, Sheikh MS, Shroot B and Reichert U (1998) Overexpression of bcl-2 or bcl-XL fails to inhibit apoptosis mediated by a novel retinoid. Oncol. Res. 10: 313-324

26. Marchetti P, Zamzami N, Joseph B, Schraen-Maschke S, Mereau-Richard C, Costantini P, Metivier D, Susin SA, Kroemer G and Formstecher P (1999) The novel retinoid 6-[3-(1-adamantyl)-4-hydroxyphenyl]-2-naphtalene carboxylic acid can trigger apoptosis through a mitochondrial pathway independent of the nucleus. Cancer Res. 59: 6257-6266

27. Deiss LP, Galinka H, Berissi H, Cohen O and Kimchi A. (1996) Cathepsin D protease mediates programmed cell death induced by interferon-gamma, Fas/ APO-1 and TNF-alpha. EMBO J. 15: 3861-3870

28. BrunkUT, Dalen H, Roberg Kand Hellquist HB (1997)Photo-oxidative disruption of lysosomal membranes causes apoptosis of cultured human fibroblasts. Free Radic. Biol. Med. 23: 616-626

29. Roberg K and Ollinger K (1998) Oxidative stress causes relocation of the lysosomal enzyme cathepsin $D$ with ensuing apoptosis in neonatal rat cardiomyocytes. Am. J. Pathol. 152: 1151

30. Shibata M, Kanamori S, Isahara K, Ohsawa Y, Konishi A, Kametaka S, Watanabe T, EbisuS, Ishido K, Kominami E and Uchiyama Y (1998) Participation of cathepsins $B$ and $D$ in apoptosis of $P C 12$ cells following serum deprivation. Biochem. Biophys. Res. Commun. 251: 199-203

31. Levy-Strumpf N and Kimchi A (1998) Death associated proteins (DAPs): from gene identification to the analysis of their apoptotic and tumor suppressive functions. Oncogene 17: 3331-3340

32. Roberts LR, Adjei PN and Gores GJ (1999) Cathepsins as effector proteases in hepatocyte apoptosis. Cell. Biochem. Biophys. 30: 71-88

33. Isahara K, Ohsawa $\mathrm{Y}$, Kanamori S, Shibata M, Waguri S, Sato N, Gotow T, Watanabe T, Momoi T, Urase K, Kominami E and Uchiyama Y (1999) Regulation of a novel pathway for cell death by lysosomal aspartic and cysteine proteinases. Neuroscience 91: 233-249

34. Ollinger K (2000) Inhibition of cathepsin D prevents free-radical-induced apoptosis in rat cardiomyocytes. Arch. Biochem. Biophys. 373: 346-351

35. Roberg K, Johansson U and Ollinger K (1999) Lysosomal release of cathepsin D precedes relocation of cytochrome $c$ and loss of mitochondrial transmembrane potential during apoptosis induced by oxidative stress. Free Radic. Biol. Med. 27: $1228-1237$

36. Neuzil J, Svensson I, Weber T, Weber C and Brunk UT (1999) $\alpha$-tocopheryl succinate-induced apoptosis in Jurkat $T$ cells involves caspase-3 activation, and both lysosomal and mitochondrial destabilisation. FEBS Lett. 445: 295-300 
37. LiW, Yuan X, Nordgren G, Dalen H, Dubowechik GM, Firestone RA and Brunk UT (2000) Induction of cell death by the lysosomotropic detergent MSDH. FEBS Lett. 470: $35-39$

38. Kang JX, Li Y and Leaf A (1997) Mannose-6-phosphate/insulin-like growth factor-II receptor is a receptor for retinoic acid. Proc. Natl. Acad. Sci. USA 94: $13671-13676$

39. Kang JX, Bell J, Beard RL and Chandraratna RAC (1999) Mannose-6phosphate/insulin-like growth factor-II receptor mediates the growth-inhibitory effects of retinoids. Cell Growth Differ. 10: 591-600
40. Green DR and Reed JC (1998) Mitochondria and apoptosis. Science 281: $1309-1312$

41. Kornfeld S (1989) The biogenesis of lysosomes. Annue. Rev. Cell Biol. 5: 483525 